\title{
LOS PROBLEMAS DE UNA IGLESIA RURAL A FINES DEL SIGLO XV A TRAVÉS DE UN LIBRO DE VISITAS
}

\author{
ALFONSO FRANCO SILVA \\ Universidad de Cádiz
}

\begin{abstract}
SUMARIO
1. Villagarcía de la Torre: un dominio de los Ponce de León.- 2. Las visitas de 1491 y 1495 .- 3 . Conclusiones.
\end{abstract}

No es frecuente encontrarse con libros de visitas parroquiales en los siglos bajomedievales, éstos, por lo general, comienzan a aparecer desde mediados del siglo XVI, y es muy raro que se hayan conservado antes de esta última centuria ${ }^{1}$. Por consiguiente, la carencia de fuente documental tan preciosa nos priva de conocer la situación en que se hallaban las iglesias castellanas en la Baja Edad Media, en particular los numerosísimos templos rurales, y así nada o casi nada podemos saber sobre sus bienes de fábrica, los objetos litúrgicos que poseían, el momento en que comenzaron a edificarse y las diversas fases de su construcción etc. De esta manera, toda una serie de aspectos relacionados con el clero secular, y sobre todo con el estado en que se encontraban sus templos, se nos escapan a nuestro conocimiento. Por fortuna, el feliz hallazgo de dos libros de visitas correspondientes a los años de 1491 y 1495 , y que tuvieron como escenario

\footnotetext{
'Tengo noticias de que se encuentra otro libro de visitas del siglo XV en la iglesia parroquial de Trigueros (Huelva).

"Anuario de Estudios Medievales". 28 (1998)
} 
la iglesia parroquial de Santa María de Araceli de la villa extremeña de Villagarcía de la Torre - hoy en la provincia de Badajoz - me van a permitir trazar un breve panorama sobre cual era la situación en que se encontraba un modesto templo rural a fines de la Edad Media y que, con toda seguridad, no difería demasiado de la de otros muchos de las mismas características situados a lo largo y ancho de la geografía del reino castellano ${ }^{2}$.

\section{Villagarcía de la TORRE: UN DOMINIO DE LOS PONCE DE LEÓN}

No es mucho lo que sabemos sobre este pequeño pueblo extemeño, próximo a la villa de Llerena. El profesor José Luis del Pino, en su obra sobre Extremadura en las luchas politicas del siglo $X V$, afirma que a lo largo del siglo XIV Villagarcía de la Torre estaba sometida a la influencia de dos jurisdicciones, la realenga y la de la Orden de Santiago, que se disputaron el poder sobre el lugar hasta que, en 1386, Juan I compró a la milicia santiaguista su mitad, y lo entregó entero en donación al maestre García Fernández ${ }^{3}$. Se mantuvo en poder de la familia de este último personaje hasta que, a mediados del siglo XV, pasó a la jurisdicción del linaje andaluz de los Ponce de León, cuando uno de los miembros de esta familia, Luis Ponce contrajo matrimonio con Teresa de Guzmán nieta y última descendiente del maestre García Fernández ${ }^{+}$. A fines del siglo XV, cuando se llevaron a cabo las visitas episcopales a su iglesia, Villagarcía de la Torre estaba gobernada por don Pedro Ponce de León, hijo y sucesor del primer Ponce, don Luis, y de su esposa Teresa. Para ser más exactos don Pedro acababa de fallecer un año antes, en 1490, y le había sucedido su hijo don Luis, padre de don Rodrigo Ponce de León, primer duque de Arcos, heredero de

\footnotetext{
'Se hallan en el Archivo de la Nobleza (Toledo). Sección Osuna, leg. 192. $3^{17}$.

3osé Luis DEL PINO García, Extremadura en las luchas políticas del siglo XV. Badajoz, 1992, pp. 114-115. De interés sobre el tema el trabajo de Emilio CABRERA MuÑoz, Los señorios de Extremadura en el siglo XV. "Actas del congreso Hernán Cortés y su tiempo (14851985)". Editora regional de Extremadura, 1987, pp. 132-145.

tIbidem. Ver también a este respecto Miguel Ángel LADERO QUESADA. Andalucia en el siglo XV. Madrid. 1973, p. 22.
} 
los extensos dominios andaluces del marqués de Cádiz $z^{5}$. Don Luis Ponce heredó de su padre un modesto mayorazgo formado por Villagarcía de la Torre y su fortaleza, una serie de heredamientos y tierras en término de la villa de Usagre, y por último dos dehesas - La Torre y La Famenara- que se hallaban en el alfoz de Llerena". La escasa renta que le proporcionaban estos dominios fue la causa que explica el hecho de que don Luis accediera gustoso al matrimonio con doña Francisca, la hija bastarda del marqués de Cádiz, con la esperanza de hacerse con la jefatura del linaje principal y, desde luego, con el riquísimo patrimonio de la $\mathrm{Casa}^{7}$. Sus deseos, sin embargo, se vieron frustrados por la última decisión adoptada por su suegro días antes de morir, en 1492, cuando nombró heredero único de su mayorazgo a su nieto don Rodrigo, un niño de poco más de dos años ${ }^{8}$. De todas formas, ya que no iba a quedar al frente de la Casa, don Luis pensó que podía gobernar los estados de su suegro actuando como tutor de su hijo durante la minoría de edad de éste. También aquí su ambición se vería frutrada, pues don Rodrigo había destinado a su esposa, Beatriz Pacheco, como tutora y curadora de la persona y bienes de su nieto". El señor de Villagarcía no se dió, sin embargo, por vencido, y, tras la muerte de su suegro, bajo el pretexto de que él era el padre del nuevo duque de Arcos, se enfrentó durante varios años a la duquesa-tutora, con la esperanza de que si no podía alcanzar la gobernación de todos los dominios del linaje, al menos trataría de conseguir la administración de una buena parte de ellos. Al final, y tras una larga serie de acontecimientos, don Luis pudo hacerse con la jurisdicción de las villas atlánticas de Rota y Chipiona que logró mantener hasta el año 1523, en que se vió obligado a renunciar a ambos pueblos en favor de su hijo, el duque de Arcos, que le compensó con la

${ }^{5}$ El testamento de don Pedro en Archivo de la Nobleza (Toledo), Sección Osuna, leg. 192. $3^{21}$. El testamento es de un gran interés. Se mandó sepultar precisamente en la iglesia parroquial de la villa. en la capilla principal en la que se ya se hallaba su esposa Leonor de Figueroa. fallecida unos años antes. Fundó dos capellanías en la iglesia, a las que dotó muy generosamente. y reparó por completo el hospital que había en la villa. $3^{21}$

"La fundación de mayorazgo la llevó a cabo don Pedro en su testamento. Osuna. leg. 192.

${ }^{7}$ Miguel Ángel Ladero QueSAda, Cádiz de señorío a realengo, en "Estudios de Historia y Arqueología Medievales". X (1994), Cádiz. p. 117.

${ }^{8}$ Ibidem. A don Luis le había seducido extraordinariamente el primer testamento de don Rodrigo, otorgado en 1488, en el que nombraba sucesora a su hija Francisca.

"Ibiclem. 
gobernación de Zahara de la Sierra, Mairena y Pruna ${ }^{10}$. Tras su muerte, en 1527, Villagarcía de la Torre pasará a formar parte de la rama principal del linaje, pues la hereda su hijo Rodrigo, y en ella continuará hasta la disolución de los señoríos en el siglo XIX.

De esta manera, Villagarcía de la Torre se convierte en un enclave señorial de los Ponce de León en tierras extremeñas, muy alejado, por tanto, de los dominios patrimoniales de la familia que se hallaban, como es notorio, en el reino de Sevilla. Esta es la razón que explica el que me haya detenido a exponer todos estos hechos, con la finalidad de centrar al posible lector en el tema que pretendo desarrollar en estas páginas, y que no es otro que el estudio de dos visitas parroquiales que el episcopado pacense realizó a fines del siglo XV, y que se recogen en un pequeño cuaderno que se conserva en muy buen estado.

\section{LAS VISITAS DE 1491 Y 1495}

El 14 de agosto de 1491 se presentó en Villagarcía de la Torre el bachiller Clemente López de Frias, capellán de los Reyes Católicos, canónigo, provisor oficial y vicario general del obispado de Badajoz por el obispo don Bernardino López de Carvajal, que a la sazón se encontraba de embajador de Isabel y Fernando en la corte pontificia de Roma. El vicario general tenía plenos poderes para realizar una visita a la parroquia de Santa María de Araceli. Hacía muchos años que esta iglesia no había recibido visita alguna, cuando la obligación más importante que tenía el obispo era precisamente visitar la diócesis, y por tanto en la sede pacense se desconocía totalmente la situación en que se encontraba ${ }^{11}$. En primer lugar, López de Frias y sus acompañantes quisieron ser informados de los recursos de los que disponía la iglesia para sostenerse. Pronto comprobaron que los bienes de fábrica eran muy escasos:

- Tres viñas, una se hallaba a la ribera y la tenía a censo anual Fernand Martín por la cantidad de 36 mrs., otra al campo de la Vieja,

\footnotetext{
${ }^{10}$ Alfonso Franco Silva, La organización municipal de Chipiona a través de sus ordenanzas, "Gades", 22 (Cádiz, 1997), p. 342.

"Sobre los libros de visitas es de gran interés el capítulo que escribe M. MARTín RiEgo en Historia de la Iglesia de Sevilla, dirección de Carlos Ros, ed. Castillejo, Sevilla, 1992, pp. 562567.
} 
también dada a censo perpetuo a Alonso de Aguilar por 35 mrs., y finalmente otra a la Maimona que la llevaba Juan Prieto por $50 \mathrm{mrs}$. anuales.

-Otra viña en Valdehenares, entregada a Juan González por $50 \mathrm{mrs}$. de censo perpetuo, que se obligó a dar el mayordomo de la iglesia por el día de San Pedro.

Estas viñas no se hallaban arrendadas hasta el día en que se llevó a cabo la visita pastoral. Fue el propio provisor quien las remató en pública subasta a las personas mencionadas.

La iglesia era propietaria también de una pequeñísima cabaña ganadera formada por dos vacas y una becerra, que habían sido donadas por dos feligreses, y que se encontraban en poder de Juan García, mayordomo de la fábrica del templo.

Finalmente los inspectores eclesiásticos anotaron en el haber de la parroquia una bula de perdones de cardenales con diez sellos para cinco fiestas del año.

La visita se trasladó posteriormente al interior del propio templo. El provisor se detuvo en el sagrario para ordenar que en adelante la hostia consagrada se ofreciese a los fieles entera, y no se dividiese en partes como hasta entonces se hacía. Entre los objetos litúrgicos que poseía la iglesia se encontraron los siguientes:

- Una cajita en la que estaba el Corpus Christi, y otra caja mayor en la que se hallaban ciertas reliquias, que no se sabía a quien pertenecían, y dos paramentos de zarzahán ${ }^{12}$.

- Una caja de plata en que estaban los óleos de los enfermos con su cruceta encima.

-Una cruz de plata con su pie grande, que pesaba 17 marcos.

- Una cruz pequeña con su crucifijo y pie, todo dorado de plata, con dos escudos de las armas de los Figueroas y Jesucristos de esmaltes.

-Una sobrecopa dorada con una cruz encima con su crucifijo y ciertos esmaltes.

-Un cáliz que tenía en la manzana ciertas armas de los linajes Mejía y Figueroa de esmaltes, tenía la copa dorada y la figura de un cordero en la patena, pesaba dos marcos y medio.

\footnotetext{
${ }^{12}$ El zarzahán era una especie de tela de seda, delgada como el tafetán y con listas de colores.
} 
-Otro cáliz todo blanco con su patena y el de la capellanía que dejó el clérigo Fernán Martín.

-Otro cáliz, también blanco, que tenía en la manzana una tiara y unas llaves.

-Otro cáliz pequeño que tenía en el pie una imagen de Nuestra Señora y en la otra parte un crucifijo.

-Un incensario de plata.

-Dos cruces de metal grandes y otra cruz pequeña.

- Tres aras con sus corporales.

- Una palía de cendal verde con unas granadas en la orilla ${ }^{13}$.

-Una vestimenta de zarzahán con sus corporales.

-Una casulla de carmesí "vellutado" con sus cenefas de trenas.

-Otra casulla vieja de zarzahán.

-Otra casulla vieja, también de zarzahán, con su estola y manípulo.

-Otra casulla de damasco blanco con una cinta morisca por cenefa y su estola.

-Dos almáticas viejas ${ }^{14}$.

-Otras dos almáticas pequeñas para muchachos, también de zarzahán.

-Una capa colorada de algodón y lino con sus cenefas.

- Una capa azul de terciopelo con sus cenefas y las armas de don Pedro Ponce de León en la capilla ${ }^{15}$.

- Un pedazo de cendal amarillo que tendrá dos varas.

- Un velo morado morisco.

- Una capa de requiem de lienzo negra.

- Cinco frontales de lienzo pintado. altares.

-16 pares de manteles de todas suertes con los que están en los colores $^{16}$.

-22 pares de tovajas labradas de lienzo de diversas maneras y

-Dos almas de lienzo.

\footnotetext{
${ }^{13}$ La palia era un lienzo sobre el que se extendian los corporales para decir misa.

${ }^{14}$ La almática, también llamada dalmática, era una vestidura sagrada que se ponía encima del alba.

${ }^{15} \mathrm{La}$ capilla era una capucha sujeta al cuello de la capa.

"La tobaja era una toalla.
} 
-Dos casullas de lienzo.

- Cuatro vestimentas de lienzo con todos sus aparejos y una casulla negra pardilla.

-Un velo de lienzo con sus listas cárdenas.

-Una manga de la cruz pintada con figuras de ángeles.

- Dos campanas grandes y una campanilla.

- Una cortina sobre los altares de la mano derecha.

- Una rueda de campanilla.

- Un misal romano de papel nuevo, pertenece a las monjas.

-Otro misal.

- Un breviario de Cartaneja que está en el atril con una cadena.

-Otro manual de misas votivas.

- Un santoral en dos cuerpos muy viejos y sin tablas.

-Un salterio.

-Unas cinco historias.

-Un libro pasionero y oficiario.

-Un colectario.

-Una regla.

-Unas horas de Nuestra Señora de lectura y canto de todas las fiestas del año.

-Un dominical de lectura y canto.

-Un oficiario dominical.

-Una lámpara.

-Dos tapetes, uno que está al pie del altar y otro que está detrás del atril donde cantan.

-Un portapaz y un atrillejo de palo.

Una vez finalizada la visita, el provisor advirtió al párroco que había necesidad de llevar a cabo una serie de reformas para el mejor funcionamiento de la iglesia y de los oficios litúrgicos que en ella tenían lugar. En primer lugar, había que reparar en las delanteras la capa bermeja, y sobre todo rehacer las gradas del altar de San Marcos, que habían sido derribadas para dar sepultura a Pedro Martín. En adelante prohibió que se derribasen esas gradas para enterramientos, bajo pena de excomunión y multa de 200 mrs. que percibiría la fábrica del templo. Por otro lado decidió también que la pila de bautismo había que hacerla más ancha, ya que era muy pequeña, a fin de que las criaturas recibiesen el bautismo sin peligro alguno. Señaló así mismo la necesidad de disponer de dos candeleros grandes de azófar para el altar, y que se labrase una verja de hierro por donde corriese el paño que 
cubría el retablo. También indicó que había que trasladar la lámpara desde el lugar en que se encontraba, y colgarla en la dirección del crucifijo, y como se hallaba maltratada sugirió la compra de una nueva de vidrio, en que se depositase el aceite, y tirar, por tanto, la que tenían de barro. El provisor ordenó también que se quitasen del altar mayor los dos pies de madero en que se ponían las cruces, y se sustituyesen por otros bien hechos de madera, o de lo que mejor se pueda alcanzar y sea honesto. Finalmente sugirió también que se pintase y reparase la pared de la puerta principal que estaba frontera del altar mayor.

Había, por tanto, muchas reparaciones que hacer. Sin embargo, el gran problema que presentaba la iglesia de Villagarcía era el que planteaban las sepulturas. Por una parte, el provisor observó que la causa principal de que el templo estuviese casi siempre sucio lo constituía la tierra, procedente de los frecuentes enterramientos que en ella se hacían. A fin de evitar tal desarreglo, el clérigo ordenó que en adelante, y bajo pena de excomunión, se cerrasen las sepulturas en el plazo de un mes, después de que fuese enterrado el difunto, y que se cubriese de ladrillos todo el suelo de la iglesia. De esta manera se pensó que estaría más limpia. Sin embargo, nunca hasta entonces se había cobrado nada por las inhumaciones, cuando en otras villas cercanas sí se hacía. El provisor se vió entonces en la obligación de resolver definitivamente el problema de los enterramientos, y así estableció una jerarquía de valores de las tumbas según el lugar en que se encontrasen dentro del templo. Así la persona que eligiese enterrarse entre la capilla principal y el coro debería satisfacer la cantidad de $600 \mathrm{mrs}$., si la tumba en cuestión se destinaba a panteón familiar, pero si únicamente la quería para él solo, entonces pagaría la mitad, quedando de nuevo ese lugar a disposición de la iglesia una vez pasado un período preceptivo de tiempo. Desde el coro hasta la puerta principal del templo las tarifas disminuían, $200 \mathrm{mrs}$. para el entierro de un solo cuerpo y 400 para panteón familiar. Esta última se entendía, como era lógico, a perpetuidad. Pero ¿qué hacer con aquellas sepulturas que ya estaban ocupadas? No hubo innovación al respecto, los familiares del muerto podrían siempre disponer de ellas, pero, eso sí, cuando hubiese necesidad de abrirlas para depositar un nuevo cuerpo tendrían que pagar las cantidades ya mencionadas, según el lugar en que se encontrasen, satisfaciendo además $60 \mathrm{mrs}$. por el derecho de apertura. Todos los ingresos que se recibiesen por este concepto irían destinados, como era natural, a la fábrica de la iglesia, quedando el mayordomo de ella en la obligación de anotarlos en sus libros, bajo pena de excomunión mayor si no lo hacía. 
Esta innovación, introducida por la jerarquía eclesiástica pacense, en cuanto al pago por tener sepultura propia en la iglesia, suscitó duras protestas por parte del concejo de Villagarcía que estimó que los precios a pagar por esos enterramientos eran muy altos. El provisor se vió obligado entonces a moderarlos, y así ordenó que aquellas sepulturas familiares que se habían fijado en la cantidad de $600 \mathrm{mrs}$. pagasen sólo 400 , y las que estaban en esta última satisfaciesen sólo la mitad.

Cuatro años más tarde, el 3 de febrero de 1495, Villagarcía recibió una nueva visita episcopal. Esta vez el visitador fue fray Pedro González de León, obispo de Sidonia y del Consejo Real, provisto de la correspondiente licencia que para tal fin le había dado el provisor de la ciudad de Badajoz, Alonso de Mariana. Habían transcurrido muy pocos años desde la primera, y por tanto pocas innovaciones iba a encontrar el prelado en esta segunda. Los bienes seguían siendo los mismos, ahora el notario apostólico Antonio Sedeño registra también nueve reses vacunas y un cahiz de trigo que había regalado a la iglesia Bartolomé Sánchez. En cuanto a los objetos litúrgicos sólo presentaban algunas adquisiciones:

- Una casulla de damasco con su estola y manípulo que había regalado don García.

- Una casulla de seda rasa negra que había regalado don Lorenzo.

- Un velo negro con unas cintas y sus cordones para la cruz.

-Dos cirios con sus copas grandes y sobredoradas para las fiestas que había regalado don Pedro Ponce de León.

- Otros cirios blancos para los oficios de cada día.

-Otros cirios negros de requiem.

- Dos cetros blancos con sus manzanas doradas.

-Otros cetros negros de requiem.

- Una capa negra de requiem.

- Una custodia dorada.

- Un libro llamado manual para dar los sacramentos.

Todos estos objetos, junto con los demás ya mencionados en la primera visita, se entregaron al mayordomo de la fábrica de la iglesia, Pedro González de Fregenal.

Sin embargo, la novedad más importante que presenta esta visita con respecto a la anterior es que por primera vez se fiscalizaron las cuentas del mayordomo de fábrica. De esta manera hemos podido saber que el coste de la visita episcopal de 1495 ascendió a la cantidad de 337 mrs., cifra que 
entraba dentro de los términos normales de la época ${ }^{17}$. En realidad la revisión de las cuentas del mayordomo fue más bien resultado de la visita, ya que se hizo unos meses después por parte del vicario de la iglesia, ayudado en esta tarea por los dos alcaldes ordinarios de la villa y por el mayordomo del señor de ella, don Luis Ponce de León. Se inspeccionó con detalle el estado de la hacienda parroquial desde septiembre de 1494 hasta julio del año siguiente con resultados altamente satisfactorios. La administración había sido excelente, solo se encontró un alcance de $420 \mathrm{mrs}$. que el mayordomo pagó de inmediato a su sucesor en el cargo Pedro González de Fregenal.

La revisión de las cuentas del mayordomo ofrece un extraordinario interés, porque este oficial anotó minuciosamente todos los gastos que había hecho para el sostenimiento de la iglesia desde el 26 de septiembre hasta su cese. De esta manera hemos podido conocer con todo detalle en qué se gastaba el modesto presupuesto de una parroquia rural a fines de la Edad Media, capítulo este, por cierto, del que sabe bien poco, por no decir nada. ¿Cuáles eran las necesidades de una iglesia a fines del siglo XV? Para responder a este pregunta de manera adecuada es preciso registrar una por una todas las partidas de gastos que el mayordomo anotó en su cuaderno y que reflejan de manera muy clara todas aquellas cosas que eran fundamentales para que el templo cumpliese bien su función. Estas eran las siguientes:

- En primer lugar compró papel para el cuaderno en el que registraría todos los gastos que iba a hacer al servicio de la iglesia, le costó tres mrs.. incienso.

-El día de San Mateo gastó tres mrs. y medio en media onza de

-El mismo gasto de incienso para el día de San Miguel. septiembre.

-Compró jabón por valor de 8 mrs. para el gasto del mes de

-Compró un serón para el servicio de la iglesia por 40 mrs.

\footnotetext{
${ }^{17}$ Muy normal si la comparamos con algunas de las comidas que los regidores de un cabildo municipal celebraban de vez. en cuando en la misma época. Valga como ejemplo de ello la comida que celebró el cabildo municipal de Morón de la Frontera en 1468. que multiplicó por más de tres la cantidad que importó la visita episcopal a Villagarcía. Alfonso Franco SiLva. La Hacienda de Morón de la Frontera (1456-1480) en La Banda Morisca durante los siglos $X I I I, X I V y X V$, Sevilla. 1996. p. 227. Desde luego que el patrimonio de un concejo solia ser muy superior en bienes al de la fäbrica de una iglesia.
} 
- Siguiendo el mandato del provisor que había visitado la iglesia compró por $31 \mathrm{mrs}$. cien ladrillos para cubrir el suelo del templo.

-Compró por ocho mrs. un tobanillo para la obra de la iglesia.

-Compró dos sogas por diez mrs. para esa misma obra cuando se pusieron los maderos.

-Pagó 50 mrs. de jornal y manutención al albañil Torrero por revestir el suelo con ladrillos, y $23 \mathrm{mrs}$. a cada uno de los dos peones que le ayudaron en esa tarea. Trinidad.

-Tres mrs. que gastó en media onza de incienso el día de la

-El sábado víspera de la Pascua del Espíritu Santo otros tres mrs. por el incienso.

- Lo mismo el día de Pascua.

-Al lunes siguiente otra onza por siete mrs.

- El martes de Pascua media onza.

-El día del Corpus Cristi una onza.

-Se compró por cuatro reales - 139 mrs.- un álamo para construir los bancos de la iglesia. bancos.

- Se pagó real y medio a un carpintero por hacer la hechura de los

-El día del Corpus, una de las festividades litúrgicas más solemnes de la iglesia católica, los gastos eran mayores porque había que darles una comida a todos los clérigos de la villa como commemoración de ese día. El gasto fue de $185 \mathrm{mrs}$., repartidos de la forma siguiente: $40 \mathrm{mrs}$. en dos gallinas, $45 \mathrm{mrs}$. en un cabrito, $64 \mathrm{mrs}$. por cuatro azumbres de vino a 16 mrs. el azumbre, carne de carnero por valor de $26 \mathrm{mrs}$., y diez mrs. en tocinos, especias y otras vituallas.

- Se le pagó también al librero Sebastián por los libros que trajo.

- Se le pagó mil mrs. al albañil Alonso Giraldo para en cuenta de los ladrillos que hacía para la iglesia.

-El lunes de Pascua se gastó siete mrs. en una onza de incienso.

- 126 mrs. por tres libras de cera - a 42 mrs. la libra - para gastar por menudo.

- Seis mrs. en alfileres para el monumento que se hacía en ese día, y cinco mrs. en medio azumbre de vino para los hombres que le ayudaron a elaborar el monumento.

-46 mrs. al pintor Alonso Valdés por pintar el pie de la Cruz.

$-43 \mathrm{mrs}$. por un moscadero para la iglesia. 
-31 mrs. que se pagaron a un hombre por desplazarse a Zafra y recoger el monjil, es decir el hábito que había regalado a la iglesia don Lorenzo Suárez de Figueroa.

$-50 \mathrm{mrs}$. a una persona por adobar los bancos del templo y poner el paño del retablo, y $22 \mathrm{mrs}$. a otro que le sirvió en este menester.

- Se compraron dos estacas de hierro por $31 \mathrm{mrs}$. para poner la verga de hierro que estaba en el paño.

-15 mrs. por 15 anillos que llevaba el paño. el óleo.

- Se le pagó un real al sacristán cuando se desplazó a Zafra a por un libro.

-Se pagó otro real al capellán Juan González por una "tobija" para

- Se pagó doce mrs. al herrero Juan González porque adobó un badajo de la campana. de vino.

- Gastó el día en que trajeron los maderos 26 mrs. para un azumbre

- Diez mrs. por una carga de leña para lavar los paños para la Pascua del Espíritu Santo.

- Trece mrs. por una libra y media de jabón.

-Pagó 2.100 mrs. por los escaños que están en la iglesia, y otros 35 que gastó él y el capellán Alonso Gallego el día que fueron a igualarlos.

-Pagó 62 mrs. a Fernando Monroy por traer los escaños, y otros ocho el último día que se trajeron.

- Media onza de mrs. que costó tres mrs. y medio para el día de la Ascensión.

- Se le pagó a Torrero doce mrs. porque labró el cepo o cepillo para recoger las limosnas, y otros 50 al herrero Juan Sánchez porque hizo la chapa y cerradura del mismo.

-Se le pagó 24 mrs. a un hombre que sirvió al albañil cuando se solaron las sepulturas, y otros ocho al joven que le había servido.

-Gastó un real en ladrillos para solar las sepulturas.

- Compró dos sogas por doce mrs. para las campanas.

- Compró por nueve mrs. una libra de jabón.

- Pagó la mitad de 19.600 mrs. que importó el metal de la campana y hechura de ella.

-250 mrs. que importó el gasto que se hizo el día en que se celebraba el oficio de tinieblas. 
-Pagó 130 mrs. al herrero Juan González por la verja de hierro que hizo para el paño del retablo.

-Compró 14 libras de cera -a 42 mrs. la libra- que costaron 588 mrs. para gastar durante la semana santa, y sobre todo durante el oficio de tinieblas. De esta cera el mayordomo llevó a Llerena siete libras y media para que le elaborasen cirios y velas, pagó cuatro mrs. por cada libra de hechura, en total $30 \mathrm{mrs}$.

-Compró 22 mrs. en limas y naranjas para el monumento.

-Pagó cuarenta mrs. al herrero Juan Sánchez porque hizo clavos para los paramentos y adobó las cadenas de la lámpara.

-Otros $43 \mathrm{mrs}$. a Torrero porque hizo el pie de la cruz y adobó los pies de los candeleros.

- Se compraron dos cargas de leña para lavar los paños de la iglesia para Pascua.

- Se compraron dos libras y media de jabón a nueve mrs. cada libra, en total 22 mrs. y medio.

- Se compraron por doce mrs. dos cabezas de cordel para la cortina.

- Se compró media onza de incienso por tres mrs. y medio para el día de la Encarnación.

- Una onza para el domingo de Ramos.

-Otra onza para el Jueves Santo.

- Media onza para el Viernes de la Cruz ( Viernes Santo ).

- Una onza para el cirio pascual el sábado de gloria.

-Otra onza para el domingo de Resurrección.

-48 mrs. por una libra de cera para gastar por menudo.

-28 mrs. para comprar cintas a los clérigos.

- Una onza de incienso para el día de Santa Catalina.

- Media para el día de Santa María la Nueva.

-Gastó doce mrs. en comprar libra y media de jabón para la víspera de Pascua. Natividad.

- Catorce mrs. en dos onzas de incienso para la pascua de la

- Media onza para el día de Año Nuevo.

-Otra media para la festividad de los Reyes Magos.

- Pagó cien mrs. de soldada a Antonio Vaquero por llevar las varas de Nuestra Señora. iglesia.

-Gastó nueve reales -279 mrs.- en la compra de un libro para la 
- Media onza de incienso para el día de San Sebastián.

- Otra media onza para el día de Santa María de la Candelaria.

- Cincuenta mrs. por una libra de cera para la iglesia.

- Gastos que se hicieron en la comida del día de la visita episcopal: $84 \mathrm{mrs}$. en cuatro gallinas, $31 \mathrm{mrs}$. en un cuarto de carnero, $35 \mathrm{mrs}$. en un cabrito, $75 \mathrm{mrs}$. en 25 cuartillos de vino a tres mrs. cada cuartillo, veinte mrs. en pan, cinco mrs. en nabos, limas y otras cosas y $29 \mathrm{mrs}$. en una fanega de trigo.

-121 mrs. costó la encuadernación de unos libros de la iglesia.

-1248 mrs. que se pagó a un librero de Llerena para el pago de un oficio de tinieblas que hacía para la iglesia.

-Ocho mrs. por el alquiler de un asno para ir a Llerena.

- Cincuenta mrs. a Torrero por solar la iglesia durante un día.

-Otros cincuenta mrs. a Torrero por poner unas costaneras en la iglesia, y $46 \mathrm{mrs}$. a dos peones que le sirvieron en ese día ${ }^{18}$.

$-483 \mathrm{mrs}$. por siete días en que el albañil Torrero estuvo reparando los caballetes y otras cosas junto con tres peones que le ayudaron en hacer mortero, trafarcana y maderar. El albañil cobró cincuenta mrs. cada día y los peones $23^{14}$.

-23 mrs. a un peón que limpió la iglesia en un día.

- Veinte mrs. por medio día en que trabajó un trastejador que recorrió la sacristanía ${ }^{20}$.

-45 mrs. por quince docenas de cabriales para la obra de la iglesia, a tres mrs. cada docena ${ }^{21}$.

-18 mrs. por dos docenas de costaneros a nueve mrs. la docena.

- Siete mrs. por tres docenas de cabríos.

-Cincuenta mrs. por dos libras de hilo.

$-58 \mathrm{mrs}$. por catorce hazas de cal, y seis mrs. por el alquiler del asno que la trajo.

\footnotetext{
${ }^{18}$ Las costaneras eran maderos largos como vigas menores que cargan sobre la viga principal que forma el caballete de un cubierto o de un edificio.

"El caballete era la linea horizontal y más elevada de un tejado, de la cual arrancan dos vertientes.

2"Un trastejador solia ser un albañil que reponía las tejas de un edificio cuando se hallaban en mal estado.

"El cabrio o cabrial era un madero colociado paralelamente a los pares de una armadura de cejado para recibir la tablazón.
} 
- Cinco reales a un maestro que adobó los hierros de las hostias.

- Media onza de incienso para el día de San Simón y Judas.

$-31 \mathrm{mrs}$. a un hombre que fue por la manga de la cruz.

- Trescientos mrs. que cobró el mayordomo por administrar los bienes de fábrica de la iglesia.

-Cien mrs. se le pagaron a Juan Martínez Ramos por ayudar al mayordomo en su trabajo y escribir estas cuentas.

-Veinte mrs. por 85 adobes cuando se hizo la campana de la iglesia.

He aquí, bien pormenorizados, los gastos que durante un año se hicieron en la iglesia parroquial de Villagarcía de la Torre. En total 6.446 mrs. Ignoramos en cambio los ingresos que la iglesia tenía, salvo algunas partidas insignificantes que registra el mayordomo y que apenas ofrecen interés ${ }^{22}$. Ya sabemos que la iglesia era muy pobre, y así se dice claramente en el informe que acompaña a la visita. Entonces cabe preguntarse por la procedencia de estos gastos, habida cuenta de que cuando se le fiscalizaron las cuentas al mayordomo, sacados los gastos que había hecho, sólo se le encontró un alcance, es decir un debe, de $420 \mathrm{mrs}$. Por consiguiente si hay que tomar por buena esta información, y no hay razón alguna para no hacerlo, los gastos eran similares a los ingresos. Por desgracia nada sabemos al respecto sobre la procedencia de esos ingresos, porque no se registran en el cuaderno.

En cuanto a los gastos propiamente tales, observamos cómo el mayordomo anotaba con detalle todo lo que compraba, el precio que le costaba y la utilidad que el objeto en cuestión tenía para la iglesia. De esta manera podemos saber que, con excepción de los gastos extraordinarios, tales como la propia visita episcopal o la tradicional comida que con ocasión de la festividad del Corpus se daba a todos los clérigos de la villa, las principales partidas se las llevaba la propia reforma y reparación de la iglesia: la limpieza, la cubierta del suelo con ladrillos, la construcción de los

\footnotetext{
"El mayordomo Juan Sánchez solo anotó en el cargo los siguientes ingresos: la renta del bacín -es decir del recipiente o bacineta en que se pedia la limosna-. la bula y el cepo. En este último cuando lo abrieron el 22 de abril había 143 mrs. La bula de Navidad produjo 38 mrs. y la del dia de la Encarnación 40. En cuanto al bacín en octubre rentó 60 mrs.. en noviembre otros 60, en diciembre 65. en enero 58. en tebrero 60. en marzo 65. en abril otros 65. 70 en mayo y 37 en junio. Por último, el majordomo registró otro ingreso de 250 mrs. que no especifica claramente. Está claro yue la suma total de estas cantidades ni remotamente se acerca a la suma total de gastos.
} 
bancos, sus escaños, los arreglos en la lámpara y en los candeleros, la pintura, la elaboración del cepillo, la limpieza de los paños, los badajos de las campanas, etc. Había que pagar a herreros, carpinteros, albañiles. A este respecto hay que decir que el templo parroquial solía recibir alguna ayuda económica extraordinaria por parte del cabildo municipal de la villa. Así, sabemos que el concejo de Villagarcía se comprometió a pagar la mitad del importe de la campana que se compró en ese año, concretamente entregó al mayordomo la cantidad de $2.800 \mathrm{mrs}$. para esta finalidad, y además cuarenta mrs. por la maroma con la que la subieron al campanario, otros $140 \mathrm{mrs}$. para el metal de la misma, y finalmente aportó otros veinte mrs. con los que se pagó al arriero que con su asno la trajo de Llerena. La compra de la campana obligó al concejo a solicitar de los vecinos una derrama extraordinaria, se llegó a recaudar de esta manera $8.050 \mathrm{mrs}$., de los que $7.000 \mathrm{se}$ entregaron a la iglesia. Incluso se hizo cargo del real que faltaba para pagar al obispo por bendecir la campana.

Un segundo capítulo de gastos, desde luego mucho menor que el anterior pero también muy significativo, lo constituían las festividades litúrgicas, el propio culto en sí. Por lo general se trataba del incienso y la cera que se gastaba en las grandes solemnidades, tales como el Corpus Christi, el Jueves Santo, el Sábado de Gloria - en el que se adquiría un cirio pascual-y el Domingo de Resurrección. El gasto era siempre mayor en los días de la Semana Santa, en que se celebraba el famoso oficio de tinieblas, sobre todo en incienso, cera para hacer cirios y velas que se fabricaban en Llerena. La onza de incienso se solía adquirir por siete mrs., y siempre se gastaba una por cada día de esas grandes festividades. En cambio solo era preciso media onza - tres mrs. por los general, a veces tres y medio- para las celebraciones menores, como por ejemplo San Mateo, San Miguel, la Trinidad, la Pascua del Espíritu Santo, la Ascensión, la Encarnación, el domingo de Ramos, Santa Catalina, Santa María la Nueva, San Sebastián, San Simón y Judas, el día de Año Nuevo, la fiesta de los Reyes Magos y, por supuesto, las vísperas de alguno de estos días. Otros gastos, menos frecuentes sin duda pero también necesarios, eran aquellos que se hacían en la compra o encuadernación de los libros litúrgicos, en desplazamientos a pueblos vecinos - Zafra, Llerena- para asuntos relacionados con el culto y en la adquisición de instrumentos curiosos como, por ejemplo, un moscadero para espantar a las moscas.

Hasta aquí las visitas eclesiásticas y sus resultados. Sin embargo, el cuadernillo que las recoge contiene también una breve descripción, por 
desgracia incompleta, de las cuentas del mayordomo del concejo de Villagarcía, y algunas otras anotaciones de interés. Ignoro las razones que llevaron a los escribanos a recoger, junto a las visitas episcopales, este tipo de información que normalmente debería figurar en las actas capitulares, puesto que se trataba de la hacienda concejil. El hecho es que se encuentra reflejada en el cuaderno, y que nos va a permitir conocer, muy someramente por cierto ya que no está completa, no los ingresos del concejo, que por desgracia no se describen, sino los gastos que realizaba, y que, desde luego, son de primordial valor para saber en que se empleaba el dinero que entraba en las arcas de una villa rural a fines de la Edad Media. Y a este respecto, como veremos a continuación, los gastos concejiles son muy similares a los de otros pueblos en la misma época como Carmona o Morón de la Frontera, por citar sólo dos de los que conocemos bien su hacienda ${ }^{23}$.

En primer lugar las cuentas del mayordomo de la villa nos descubren la población que tenía Villagarcía en 1495. Así, según un padrón de la moneda forera, - cada vecino contribuía a ella con la cantidad de trece mrs. - sabemos que la villa contaba con 213 vecinos pecheros, y que pagaba a la monarquía 16.250 mrs. para el sostenimiento de la Santa Hermandad. A fin de recaudar esa cantidad, los dos alcaldes ordinarios, los seis regidores y el mayordomo Juan Rebollo empadronaron durante dos días a los vecinos, gastando en comida y bebida 200 mrs., que venía a ser una gratificación extraordinaria, ya que los oficiales capitulares no cobraban nada por el ejercicio de sus cargos. Esta comida constituía uno de los gastos extraordinarios del concejo, junto a los de mensajería y algunos otros. Así por ejemplo los tres mensajeros que llevaron a Trujillo el dinero destinado a la Hermandad cobraron en tres tercios $617 \mathrm{mrs}$. Uno de los recaudadores de esa contribución percibió por su trabajo 372 mrs., y 280 se le pagaron a otro porque su padrón era menor que el del anterior. Resulta curioso comprobar cómo fueron estafados los mensajeros que se desplazaron a Trujillo: una de las partidas anota que se les perdonaron tres reales falsos que les habían dado en esa villa, ya que ignoraban quien o quienes se los habían entregado. Los gastos más frecuentes que se hacían en mensajería eran los que se

\footnotetext{
${ }^{2}$ Sobre Carmona. Manuel GONZÁLEZ JIMÉNEZ, El concejo de Carmona a fines de la Eded Media (1465-1533), Sevilla, 1973. pp. 188 y ss.; sobre la de Morón ver mi artículo citado en nota 16. De gran interés también es el trabajo de Mercedes BORRERO FERNÁNDEZ, Las haciendas de los concejos rurales sevillanos, en "Actas del II Coloquio de Historia Medieval Andaluza. Hacienda y comercio". Sevilla, 1982, pp. 68 y ss..
} 
destinaban a Marchena, la villa en la que residía don Luis Ponce de León, señor de Villagarcía: dos reales a Juan Lucas cuando se desplazó a esa villa, otros seis a Pedro Barrilero, otros cinco a un hombre que llevó cartas etc.. Importante fue también el gasto que se tuvo que hacer cuando la villa envió un presente a doña Francisca Ponce de León, esposa de don Luis, por haber dado a luz a su hijo Juan. El regalo en cuestión consistió en la compra de cincuenta garlinas que costaron 1.000 mrs., a veinte cada una, una carga de vino - seis arrobas- que importó $1.240 \mathrm{mrs}$., y finalmente ocho gamones que costaron $870 \mathrm{mrs}$. A este respecto, el mayordomo no tuvo ningún reparo en anotar en esta cuenta que sólo habían contribuido para adquirir el presente los vecinos pecheros de la villa ya que los hidalgos, los amos y los criados paniaguados se habían negado a ello. También fue agraciado con un presente de cinco pollos, que costaron $77 \mathrm{mrs}$. y medio, el alcalde mayor de la villa, Martín de Ávila, es decir el funcionario que ejercía la máxima jurisdicción en Villagarcía en nombre de don Luis Ponce de León.

Otros gastos realizados por el mayordomo fueron la construcción de unas pilas para la fuente de la villa, recibiendo el maestro albañil que las hizo la cantidad de 285 mrs., e importando dos reales los 200 ladrillos que fueron necesarios para la obra. Finalmente el concejo se responzabilizaba todos los años de pagar el toro que se corría por las calles de la villa el día de la fiesta de San Marcos, y de ayudar con un real a las amas de cria que se hacían cargo de criar a los niños recién nacidos que eran abandonados a la puerta de la iglesia.

\section{CONCLUSIONES}

El cuaderno, que acabamos de estudiar, nos ha proporcionado una preciosa información sobre el estado en que se hallaba un templo parroquial a fines de la Edad Media. Sin duda alguna, a falta de mejor información, puede servirnos de modelo para el conocimiento de otras muchas iglesias similares de la época. Nos encontramos ante un modesto pueblo rural, perteneciente a la jurisdicción señorial de los Ponce de León, rodeado por los dominios de la Orden de Santiago, habitado por poco más de 200 vecinos, que disponía de una iglesia parroquial que no era más que un fiel reflejo de la situación económica de la misma villa, es decir un templo pobre que servía a una comunidad también pobre. Una iglesia, en fin, que tenía 
muchas deficiencias, que estaba en mal estado, sucia, necesitada de numerosas reparaciones y arreglos, de nuevos pisos que cubrieran adecuadamente las tumbas que en ella había, de nuevos bancos para que los fieles pudieran sentarse, de unas campanas nuevas fundamentales en una comunidad rural, no sólo para la llamada a los oficios, sino también para avisar al vecindario de cualquier suceso extraordinario, y para otras muchas cosas. Con esta situación se encuentran las autoridades diocesanas que intentan, como era natural, poner un poco de orden en una iglesia que desde hacía muchísimos años no se visitaba. Y así obligan a los vecinos a pagar por disponer de tumba en el templo, algo que no se había hecho jamás, y sobre todo, tras observar los desperfectos, tratan de repararlos en la medida de las posibilidades de una iglesia con poca hacienda y muchos gastos, con una dotación escasa en objetos litúrgicos necesarios para el culto divino, y, lo que era aún peor, viejos y en mal estado. Algunas de las recomendaciones episcopales surtieron efecto, y así se adquirieron nuevas campanas, se cubrió el suelo de ladrillos, se compraron algunas lámparas, se hicieron nuevos bancos, se repararon, en fin, los techos y hasta se labró un nuevo cepillo. Todo ello a base de muchos gastos tal como reflejan las cuentas del mayordomo que demuestran que, al menos por lo que respecta a este templo, las visitas fueron extraordinariamente efectivas y útiles.

\section{RÉSUMÉ}

L'heureuse trouvaille de deux livres paroissiales, respectivement datés de 1491 et de 1495, de l'église de Sainte-Marie d'Araceli, de la ville d'Extrémadure Villagarcía de la Torre - qui se situe aujourd'hui dans la province de Badajoz - m'a permis de connaître la situation dans laquelle se trouvait un modeste temple rural à la fin du Moyen Âge. En effet, nous nous trouvons devant un modeste village rural appartenant à la juridiction seigneuriale de Ponce de León, entouré des terres de l'Ordre de Saint-Jacques, peuplé d'environ 200 habitants, qui disposait d'une église paroissiale, mais qui n'était pas le reflet fidèle de la situation économique de la ville; il s'agit d'un temple pauvre pour une communauté pauvre. Les autorités diocésaines tentent de mettre un peu d'ordre dans une église qu'on ne visite plus depuis longtemps. Effectivement, la majeure partie de recommandations épiscopales furent efficaces; on en vint à réparer assez bien l'église. 
SUMMARY

The lucky find of two parochial visitors books dating from 1491 and 1495, in the church of Saint Mary of Araceli in Villagarcia de la Torre, a village in Extremadura (now belonging to the province of Badajoz), has given an insight into the situation of a modest country temple at the end of the Middle Ages.

This modest country village, under the jurisdiction of the Ponce de León, surrounded by the domain of the Order of St. James, was inhabited by a little over 200 people. It had a parish church which reflected the economic situation of the village: a poor temple serving a poor community. The diocesan authorities tried to improve the situation of the church which had not been visited for many years. Most of the episcopal recommendations were effective and many repairs were carried out in the church. 